\title{
PERFORMANCE MEASUREMENT OF TQM USING INTEGRATED FUZZY-AHP
}

\author{
RAKESH KUMAR \& R.S. MISHRA
}

Delhi Technological University, Delhi-110042

\begin{abstract}
Performance measurement is regarded as one of the most important and critical tasks in the course of any organization. Measuring performance is the assessment of the possible impact that a proposed plan or project may have on the organizational system, together consisting of the financial, non-financial and operational aspects. The aim of this paper is to propose a performance measurement methodology based on an integrated Fuzzy-AHP approach in the context of total quality management (TQM). In the proposed methodology the criteria weights are generated by a fuzzy-AHP procedure. The fuzzy set theory is a perfect means for modeling uncertainty or imprecision arising from human mental phenomena. The usage of fuzzy sets in describing uncertainties and vagueness in different critical success factors of TQM simplifies the complex structure of performance assessment.

KEYWORDS: Performance Measurement, TQM, Multicriteria, Fuzzy, AHP
\end{abstract}

Received: Jun 08, 2020; Accepted: Jun 28, 2020; Published: Sep 01, 2020; Paper Id.: IJMPERDJUN20201008

\section{INTRODUCTION}

Performance measurement often has to deal with latent variables which were difficult to identify and define also components that may involve both quantitative and qualitative factors. Performance measurement is a complex task not only because of its wide scope but also because of the wide range of attributes that bear on its assessment, Kumar, R. et al. (2019).In terms of scope, an assessment may cover subjective and vague decisions that may affect various interest groups or stakeholders each with their own demands and needs. In view of these difficulties, methods based on fuzzy logic may be quite useful in undertaking difficult assessment procedures. The fuzzy set theory was introduced by Zadeh (1965) to express the linguistic terms in decision-making process in order to resolve the vagueness, ambiguity and subjectivity of human judgment. A fuzzy method stands very helpful to tackle precisely with complex and ill-defined performance measurement decision making problems. Very few organizations categorized themselves as having fairly TQM-driven performance management system, they were quite positive - if not yet revealing conclusive evidence - of understanding the influence of system factors on individual performance in a quality-driven context, Soltani,E. et al. (2005).G. G. Dess et al. (1984) addressed in his research that research which incorporates organizational performance (OP) must address two basic issues: (1) selection of a conceptual framework from which to define OP and (2) identification of accurate, available measures that operationalize OP. In addition, collecting data and information to coordinate and support the procedure of taking action and making decisions throughout the organization is the reason for performance measurement (Van Schalkwyk, 1998).

The subsystems like Just-in-Time (JIT), Total Productivity System (TPS), Total Productive Maintenance (TPM), Supply Chain Management (SCM), Lean Manufacturing (LM) System and many more were incorporated to the organizational system as per their fit to achieve the benchmarked performance or the targeted level of 
performance. Vanichchinchai, A., and Igel, B. (2011) mentioned that to achieve JIT delivery, quality of the whole internal operations as well as that of the external partners must be assured. Scannell et al. (2000) found that JIT purchasing significantly associated with flexibility, conformance to specification and low production cost performance. Total Quality Management (TQM) is one of them most comprehensive management approach to ensure the higher levels of performance of the organization. TQM is not limited only to ensure the quality of products but it is equally important to vigil the performance of organization and also covers wider aspects of quality product and services. British Standard Institution defines; TQM consists of a "management philosophy and company practices which aim to harness the human and material resources of a corporation within the best way to achieve the objectives of the organization". Definition of TQM by Feigenbaum's (1988) encompasses every aspect of the TQM cycle including, customer focus, process planning, process management, and process improvement. Feigenbaum's (1988) states that "a total quality system is defined as one which embraces the whole cycle of customer satisfaction from the interpretation of his requirements prior to the ordering stage, through to the supply of a product or service at an economical price and on to his perception of the product after he has used it over an appropriate period of time".

Instead of investigating the gap based on a specific theoretical view, this study is an exploratory and quantitative effort focused on the identification of sources of the gap. As objective of this study, an integrated fuzzy AHP methodology is proposed for Performance measurement of TQM system. In the proposed methodology, the weights of the assessment criteria are determined by a fuzzy AHP procedure. The rest of the paper is organized as follows: In Section 2, a literature review about multiple attribute performance measurement is briefly given. In the third section, an integrated fuzzy AHP methodology is presented. In Section 4, following the determination of the selection criteria and alternatives, the proposed methodology is applied to a industrial problem. Finally, in the last section, conclusions and suggestions for further study are given. In sum, this study provides useful insights to support the decision making for performance measurement of companies to make strategic and resource allocations for developing high quality products to improve operational performance.

\section{LITERATURE REVIEW}

Performance measurement is a critical factor for the effective management. This may stem back from the fact that without measuring something, it is difficult to improve it, Ismail Salaheldin, S. (2009) strongly recommended. Therefore, improving the organizational performance requires identifying and measuring the impact of TQM practices on it (Demirbag et al., 2006; Koh et al., 2007).Performance Measurement (PM) is the process of identifying, predicting, evaluating and mitigating the critical success factors and other relevant effects of development proposals prior to major decisions being taken. Measuring performance is an important practice for ensuring that the likely effects of new development on the organizational system are fully understood and taken into account before the development is allowed to proceed. Performance appraisal, on the other hand, is defined as, 'a formal documented system for the periodic review of an individual's performance' (Moon, 1993, p. 8); or, 'the process by which data are collected and reviewed about an individual employee's past and current work behaviour and performance' (Bratton and Gold, 1999).Performance Measurement enables organizational factors to be given due weight, along with financial, non-financial or operational factors, when planning applications are being considered. If properly carried out, it benefits all those involved in the planning process. For the production planning and other strategist with quality control responsibilities, performance 
measurement provides a basis for better decision making. The fundamental objectives of any organization are to establish and maintain competitive advantage and ensure strong organizational performance (Eisenhardt et al., 1998).

\section{Performance Measurement and TQM}

TQM practices have been successful in increasing organisational performance is that TQM serves as a link between an organisation's business or corporate strategy and its performance. TQM creates a system of checks and balances to ensure that an organisation's business strategy is successful (Prajogo and Sohal, 2006), the same pair author in year 2004 provided a multidimensional view of TQM practices in determining organizations' quality and innovation performance. TQM use to improve organizational efficiency and their effectiveness as well as to create tools to better manage the quality of products and services for their long-term customers. Pfeffer and Sutton (2006), argue that TQM practices emphasise evidence-based management that concentrates on creating visible and measurable improvements to processes, rather than on vague estimations of customer or client approval. A study presented by Ahire et al. (1996) about an analysis on the comparison for the Quality management in TQM firm versus non-TQM firms. Firms are classified as: high performance TQM firms, low performance TQM firms, high performance non-TQM firms and low performance non-TQM firms. Major reasons behind the failure of TQM effort viz. lack of management commitment, unrealistic expectations and time-frame and cost of TQM implementation, under-reliance on statistical methods, and failure to develop and sustain a quality-oriented culture are reported by authors. Measuring critical success factors (CSF) of TQM is an essential precondition to control the implementation process and to increase the chances of success, stated Hietschold, N. et al. (2014).Because there is no consensus on certain factors or a holistic framework, so Salaheldin (2009) stated that finding and selecting adequate measurement instruments is a major challenge to companies. The CSFs of TQM can be used to gain a better understanding of the practices of quality management, to determinethe existing quality position of an organization, to assign responsibilities within an organization and to supervise quality and improvement programs (Motwani et al.,1994).

\section{Multiple Attribute Performance Measurement}

Multi-criteria decision-making (MCDM) methods enable the decision-makers handle uncertainty, complexity and conflicting objectives. MCDM problems usually require both tangible and intangible factors to be evaluated. The main problem for intangible criteria is that the values for such criteria are often imprecisely defined for the decision-makers, and the desired value for the criteria are usually defined in linguistic terms. It is difficult to express the character and significance of criteria exactly or clearly in crisp methods Chou T.Y et al. (2008).Decision making in performance measurement problems can be complex and multifaceted due to the inherent barriers, volatility, uncertainty, complexity and ambiguity factors also. Moreover, decisions in performance measurement may involve many different stakeholders with different priorities or objectives. Many theories and methods of performance for conducting an evaluation with different approach have been applied in various organizations. These approaches include Balanced Scorecard, total production analysis, regression analysis, ratio analysis, Delphi analysis, Analytic Hierarchical Process (AHP), Data Envelopment Analysis (DEA) and others. Each method has its own basic concept, aim, advantages and disadvantages (Dessler, 2000). Which one is chosen by management or decision makers for assessing performance depends on the status and type of the organization. However, all the successful enterprises have some common features, including a specific vision, positive actions, and an effective performance evaluation. Since Bellman and Zadeh (1970) developed the theory of decision behaviour in a fuzzy environment, various relevant models were developed, and have been applied to different fields such as control engineering, artificial intelligence, management science, and Multiple Criteria Decision Making 
(MCDM) among others. The concept of combining the fuzzy theory and MCDM is referred to as fuzzy MCDM (FMCDM). Liou and Tzeng (2007) considered that the attributes (criteria) might exist as dependent characteristics when they used a fuzzy integral approach to integrate the performance ratings of dependent attributes. Yildirim et al. (2019) used fuzzy analytical hierarchy method to determine the weighting scores of indicators of Logistics Performance Index (LPI). It is strongly considered that LPI is accepted as an important indicator of logistical performance. The proposed model is to evaluate the LPI of the OECD (Organisation for Economic Cooperation and Development) countries within a specific time frame and compared with the existing LPI rankings. Through a managerial view Kayakutlu and Buyukozkan (2011) present an analytical framework to measure the performance factors for 3PL companies. The factors integrating the strategic and operational targets are evaluated within a framework based on four levels: performance targets, planning activities, logistics operations, and performance attributes of logistics operations. The ANP method is used to determine the most effective performance attributes. To evaluate the performance of third-party logistics (3PLs), P. Kumar et al. (2012)with the implication of an integrated model of fuzzy analytic hierarchy process (FAHP) and technique for order preference by similarity to ideal solution (TOPSIS) used. FAHP is used to assign the weight to criteria for 3PL rating in this paper. Presented work by Jiansheng Zhangab and Wei Tana (2012) shows sets up of scientific, reasonable performance evaluation system using simply AHP which is especially suitable for the small and medium 3PLs enterprise from the five levels of financial, customers, transportation, storage and technology. In service quality, Wenhua Li et al. (2017) proposed a hybrid approach based on fuzzy AHP and 2-tuple fuzzy linguistic method to evaluate in-flight service quality. Service Quality Model (SERVQUAL)as an instrument is used and a hierarchy of the evaluation index system for in-flight service quality was constructed for the study. The ratings of sub-criteria are assessed in linguistic values which are further transformed into 2-tuples and the 2-tuple linguistic arithmetic mean operator is used to obtain the average ratings of 100 respondents. Tüysüz, F., and Şimşek, B. (2017) presented Hesitant fuzzy sets-based analytic hierarchy process method for analyzing the factors affecting the performance of the branches of a cargo company and also for prioritizing them according to their level of importance.

\begin{tabular}{|c|c|c|}
\hline Intensity of Importance & Definition & Explanation \\
\hline 1 & Equal importance & Two activities contribute equally to the objective \\
\hline 3 & Weak importance of one over other & $\begin{array}{l}\text { Experience and judgment slightly favor one activity } \\
\text { over another }\end{array}$ \\
\hline 5 & Essential/Strong Important & $\begin{array}{l}\text { Experience and judgment slightly favor one activity } \\
\text { over another }\end{array}$ \\
\hline 7 & Demonstrated importance & $\begin{array}{l}\text { An activity is favored very strongly over another; its } \\
\text { dominance demonstrated in practice }\end{array}$ \\
\hline 9 & Absolute importance & $\begin{array}{l}\text { The evidence favoring one activity over another is of } \\
\text { the highest possible order of affirmation }\end{array}$ \\
\hline $2,4,6,8$ & $\begin{array}{l}\text { Intermediate values between the two } \\
\text { adjacent judgments }\end{array}$ & When compromise is needed \\
\hline $\begin{array}{l}\text { Reciprocal of the above } \\
\text { non-zero }\end{array}$ & $\begin{array}{l}\text { If activity } i \text { has one of the above } \\
\text { nonzero numbers assigned to it when } \\
\text { compared with activity } j \text { then } j \text { has the } \\
\text { reciprocal value when compared with } i\end{array}$ & A reasonable assumption \\
\hline Rationals & Ratios arising from scale & $\begin{array}{l}\text { If consistency were to be forced by obtaining } n \text { numerical } \\
\text { values to span the matrix }\end{array}$ \\
\hline
\end{tabular}

Figure 1

\section{AN INTEGRATED FUZZY-AHP METHODOLOGY}

\section{Fuzzy-AHP (FAHP)}

Amalgamation of fuzzy set theory with AHP generate fuzzy analytical hierarchical process (FAHP) and was defined by Huang and $\mathrm{Wu}$ (2005) in three steps. "The first involves using triangular fuzzy numbers to transform the ideas of experts into a positive reciprocal matrix. Second, a geometric mean method that weighs the fuzzy values for each option, with the 
established hierarchical connection and finally, a membership function for each option that developed the ranking of priorities.'In practice, AHP has two basic applications (Cheng and Li, 2002). First, the traditional use of it is to assign weights to a set of pre-determined elements (e.g criteria, factors) and second, make decision(s) out of several alternatives. When a hierarchy has only three levels, the AHP method is equivalent to the classical Simple Additive Weighting (SAW) method (which is also known as weighted linear combination or scoring methods is a simple and most often used multi attribute decision technique). We feel that the AHP method is worth utilizing when there are more than three levels in a hierarchy. For the determination of the relative importance of evaluation criteria, fuzzy-AHP can be used since it is based on pair-wise comparisons and allows the utilization of linguistic variables. From paired comparisons a relative scale of measurement is derived. Although the pair-wise comparison approach is demanding in terms of solicited input from the experts, it offers maximum insight, particularly in terms of assessing consistency of the experts' judgment. This technique is ideal for closer examination of a selected set of performance measurement criteria in total quality management context. Saaty $(1980,1994)$ listed several benefits of AHP. First, it helps to decompose an unstructured problem into rational decision hierarchy (similar to decision tree). Second, it can elicit more information from the experts or decision makers by employing the pair-wise comparison of individual groups of elements. Third, it sets the computations to assign weights to the elements. Fourth, it uses the consistency measures to validate the consistency of the rating from the experts and decision makers. It is, therefore, argued to be composed of both qualitative and quantitative substances. Saaty, T. L. (1990) stated that, "The most effective way to rationalize judgments is to take a pair of elements and compare them on a single property without concern for other properties or other elements". Pair-wise comparisons in the AHP assume that the decision-maker can compare any two elements $E_{i} E_{j}$, at the same level of the hierarchy and provide a numerical value $i j$ a for the ratio of their importance. If the element $E_{i}$ is preferred to $E_{\mathrm{j}}$, then; $a_{i j}>1$. Correspondingly, the reciprocal property; $a_{j i}=1 / a_{i j} ; a_{i j}>0$, for $i=1,2, \ldots, n$ and $j=1,2, \ldots, \mathrm{n}$ always holds. Each set of comparisons for a level with $n$ elements requires $n(n-1) / 2$ judgments, which are further used to construct a positive reciprocal matrix of pair wise comparisons

The positive reciprocal comparison matrix of criteria weights is given as:

$$
\mathrm{A}=\left[\begin{array}{cccc}
a_{11} & a_{12} & \ldots \ldots \ldots & a_{1 n} \\
a_{21} & a_{22} & \ldots \ldots \ldots & a_{2 n} \\
\ldots & \ldots & \ldots & \ldots \\
a_{n 1} & a_{n 2} & \ldots \ldots \ldots & a_{n n}
\end{array}\right]
$$

The geometric mean of each row is calculated as:

$$
Z i=\left[\prod_{j=1}^{n} a_{i j}\right]^{1 / 2} \text { for } i ; j=1,2, \ldots . . n
$$

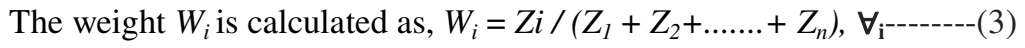

\begin{tabular}{|c|c|c|c|c|c|c|}
\hline 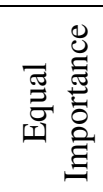 & 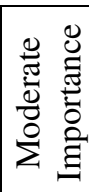 & 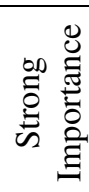 & 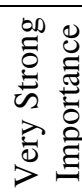 & 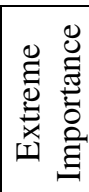 & 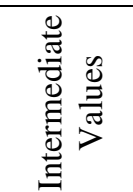 & 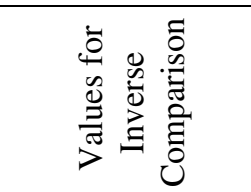 \\
\hline 1 & 3 & 5 & 7 & 9 & $2,4,6,8$ & $1 / 3,1 / 5,1 / 7 \& 1 / 9$ \\
\hline
\end{tabular}

The values in the scale of relative importance is crisp numeric values 


\section{Scaling for Fuzzy -AHP}

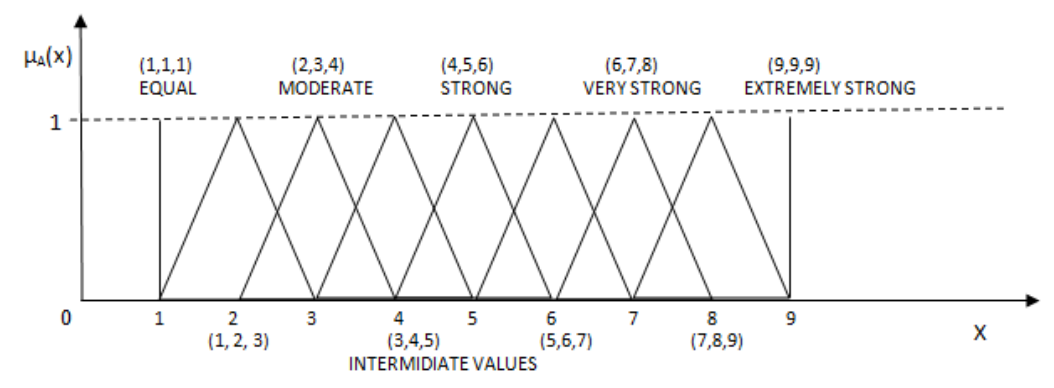

Figure 2 Fuzzy Evaluation Scale for TQM CSFs

\begin{tabular}{|c|c|c|c|c|c|c|c|c|c|}
\hline 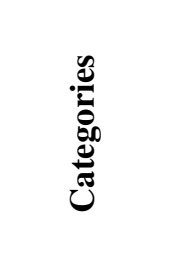 & 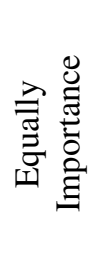 & 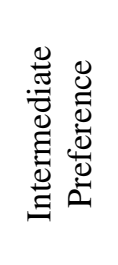 & 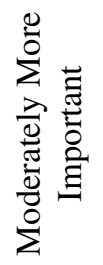 & 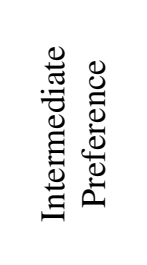 & 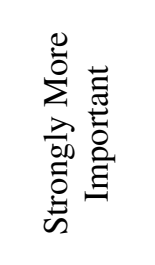 & 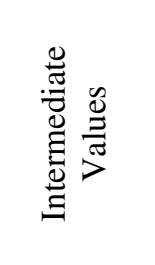 & 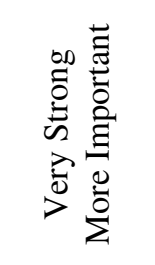 & 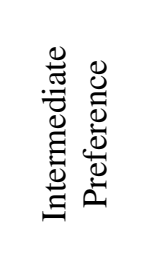 & 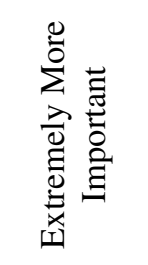 \\
\hline Triangula & $1,1,1$ & $1,2,3$ & $2,3,4$ & $3,4,5$ & $4,5,6$ & $5,6,7$ & $6,7,8$ & $7,8,9$ & $9,9,9$ \\
\hline $\begin{array}{c}\mathbf{r} \\
\text { Fuzzy } \\
\text { AHP } \\
\end{array}$ & $1,1,1$ & $\begin{array}{c}1 / 3,1 / 2, \\
1\end{array}$ & $\begin{array}{c}1 / 4, \\
1 / 3,1 / \\
2\end{array}$ & $\begin{array}{c}1 / 5,1 / 4,1 / \\
3\end{array}$ & $\begin{array}{c}1 / 6,1 / 5,1 / \\
4\end{array}$ & $\begin{array}{c}1 / 7,1 / 6,1 / \\
5\end{array}$ & $\begin{array}{c}1 / 8,1 / 7,1 / \\
8\end{array}$ & $\begin{array}{c}1 / 9,1 / 8,1 / \\
7\end{array}$ & $\begin{array}{c}1 / 9,1 / 9,1 / \\
9\end{array}$ \\
\hline
\end{tabular}

To facilitate the calculation of fuzzy weights, the following arithmetic operations of triangular fuzzy numbers are presented. A triangular fuzzy number $(\operatorname{TrFN})$ can be defined as $\mathrm{A}=(\ell, \boldsymbol{m}, \boldsymbol{u})$ where $0 \leq \ell \leq m \leq u$ as shown in Fig. 1 , and its membership function is as follows:

$$
\mu_{A}(x)=\left\{\begin{array}{l}
\frac{x-\ell}{m-\ell} \text { for } \ell \leq \mathrm{x} \leq m \\
\frac{u-x}{u-m} \text { for } m \leq x \leq u \\
0, \text { for otherwise: }
\end{array}\right.
$$

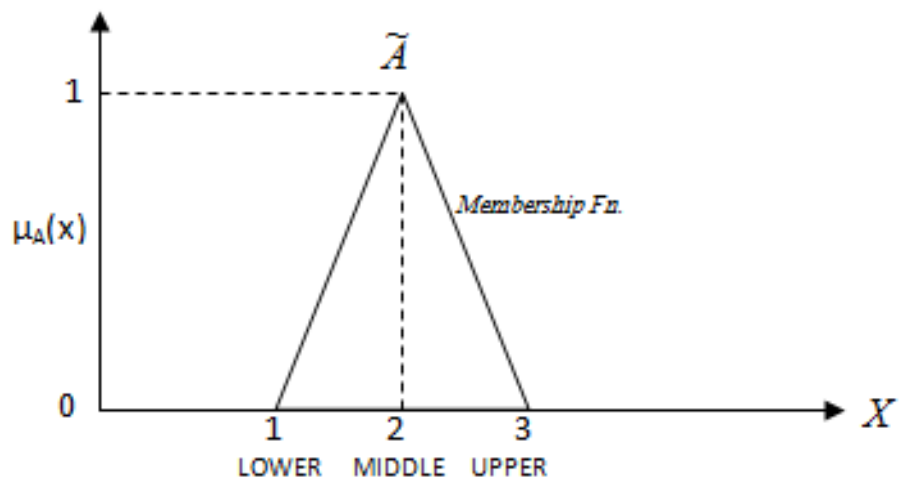

Figure 1 Membership function of $\operatorname{TrFN}$ 
Let $u=\left(\ell_{1}, m_{1}, u_{1}\right)$ and $v=\left(\ell_{2}, m_{2}, u_{2}\right)$ be two TrFNs. Where $\ell_{r} m u$ for Lower, Middle and Upper significant membership function. The interval $(\ell, u)$ expresses the closure of the support of $\tilde{A}$, and the middle significant value $m$ represents the core of $\mathcal{A}$. A real number $A \in \mathrm{R}$ can be viewed as a triangular fuzzy number.

Next to defuzzify the $\operatorname{TrFN} m=\left(\ell_{1}, m_{1}, u_{1}\right)$, the following equation canbe used:

$W_{i}=\frac{\varepsilon_{1}+m_{1}+u_{1}}{3}$

\section{STEPS OF THE PROPOSED FUZZY-AHP ALGORITHM}

The proposed method consists of some simple steps which have been outlined in the following sections. This method may be used for both group as-well-as individual decision-making.

Step I: Determining the Attributes. The attributes i.e. TQM drivers, enablers and capabilities are selected on the recommendation of analyst opinion. The attributes which have some sub-attributes are not included in the decision-making process. In other words, the final level of the hierarchical decision-making diagram (i.e., attributes) is involved in decision making.

Step II: Evaluate the relative importance of the criteria using pair-wise comparisons. The experts are required to provide their judgments on the basis of their knowledge and expertise. The experts' linguistic preferences are converted into triangular fuzzy numbers using Table 2.

Step III: Aggregate experts' individual preferences into group preference by applying the fuzzy triangular averaging operator, which is defined by

$$
a_{i j}=\frac{1}{K}\left[\alpha_{i j}^{1}(+) a_{i j}^{2}(+) \ldots \ldots \ldots+\alpha_{i j}^{j}\right]
$$

Where $\mathrm{K}$ is the number of experts and $a_{i}^{j}$

Is the evaluation of the $\mathrm{K}^{\text {th }}$ decision maker on the pair-wise importance comparison of $\mathrm{j}^{\text {th }}$ and $\mathrm{k}^{\text {th }}$ criteria.

Step IV: Obtain the fuzzy weights $\mathrm{W}_{\mathrm{i}}$. The derivation of $\widetilde{z}_{j}$ values (Eq. (2)) and fuzzy weights $\widetilde{W} j(\mathrm{Eq}$. (3)) can be detailed as follows.

Let:

$$
a_{j}=\left[\prod_{k=1}^{n} a_{j k}\right]^{1 / n} \text { and } a_{j}=\sum_{j=1}^{n} a_{j}-----------0(7)
$$

The fuzzy weight $\left(\widetilde{w}_{i}\right)$ of every attribute is computed in Eq. (3) which involves 3 sub-processes.Initially, the vector summation of every $\tilde{r}_{\tilde{i}}$ is found. Next, the inverse of summation vector is done andreplaces the $\mathrm{T}_{\mathrm{r}} \mathrm{FN}$. Finally, the $\tilde{w}_{i}$ is calculated by multiplying every $\tilde{r}_{i}$ with its reverse vector.

Step V: Defuzzify and normalize the triangulalr fuzzy weights.

To defuzzify the TrFN in Eq. (8), the following equation is used: 
$W_{i}=\frac{t_{1}+m_{1}+w_{1}}{3}$

And, to normalize the crisp weights Eq. (9) is used: $W_{j}=\frac{w_{j}^{5}}{\Sigma_{j=1}^{\eta} w_{j}^{n}}, j=1,2, \ldots \ldots . n$

\section{MODEL VALIDATION: A CASE OF INDIAN FMCGS COMPANY}

Fast Moving Consumer Goods (FMCGs) industries captures oligopolistic market, so being sustain in the global market, recurrently measurement of performance become essential task. In order to determine the performance of the implemented total quality management which strongly depends on its critical success factors and capabilities, the linguistic data is collected including all levels of management viz, Low level, Medium level and Top level through questionnaire. The involvement of all three levels is to nullify the biasness of the response provided and meet the requirements of TQM as well and observed that mostly using chomskyan linguistics. The vision behind involvement the employees of three levels to form a quality circle. As it is well known fact that the quality circle helps to find out relationship between different factors in the organization and their effect on each other so that we can find out major and minor factors based upon ranking which management can take action to improve organization effectiveness. Zbaracki (1998) the concept of TQM provides a simple and essential description of quality management that allows middle and upper level managers to oversee product and service quality in direct and uncomplicated manner. The primary objective associated with modeling for performance measurement is to identify the various critical factors, interacting operations in a realistic manner. Achieving this objective is complicated by existing TQM barriers, if any. Given the complexity of operations and the uncertainty associated with several of these factors, FAHP was identified as an important decision-making tool for use in understanding, quantifying, and improving performance. During an actual study of organization and its operation environment, a decision maker will monitor multiple performance measures. These include existing TQM drivers, enablers, and capabilities for all types of factors. TQM drivers represent the bottom line and are considered the most important performance measure. TQM enablers, which is positively correlated with drivers, and both reinforce the capability of TQM. In total 14 attributes were considered for 03 criteria for the present condition (Table 1). On the basis of collected information hierarchy is developed for the evaluation (Figure 1).

Table 1: Performance Measurement Criteria of TQM

\begin{tabular}{|c|c|c|c|}
\hline Level I & Level II & Level III & Level IV \\
\hline GOAL & CRITERIA & ALTERNATIVES & \\
\hline \multirow{14}{*}{ 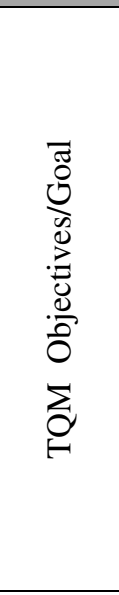 } & \multirow{7}{*}{$\begin{array}{c}\text { TQM } \\
\text { Drivers }\end{array}$} & Top Level Management & \multirow{14}{*}{ 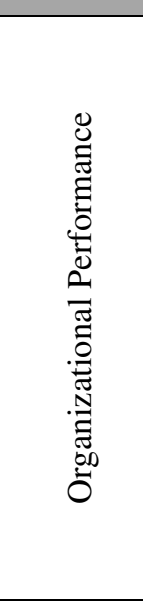 } \\
\hline & & Customer Focus & \\
\hline & & Continuous improvement and innovation & \\
\hline & & Supplier management & \\
\hline & & Employee involvement & \\
\hline & & Quality Information /Information Quality & \\
\hline & & Benchmarking & \\
\hline & \multirow{3}{*}{$\begin{array}{c}\text { TQM } \\
\text { Enablers }\end{array}$} & Culture and communication & \\
\hline & & Employee Encouragement and Motivation & \\
\hline & & Training and education & \\
\hline & \multirow{4}{*}{$\begin{array}{c}\text { TQM } \\
\text { Capabilities }\end{array}$} & Zero Defect & \\
\hline & & Waste Reduction & \\
\hline & & Continuous Improvement Process & \\
\hline & & Performance Improvement & \\
\hline
\end{tabular}




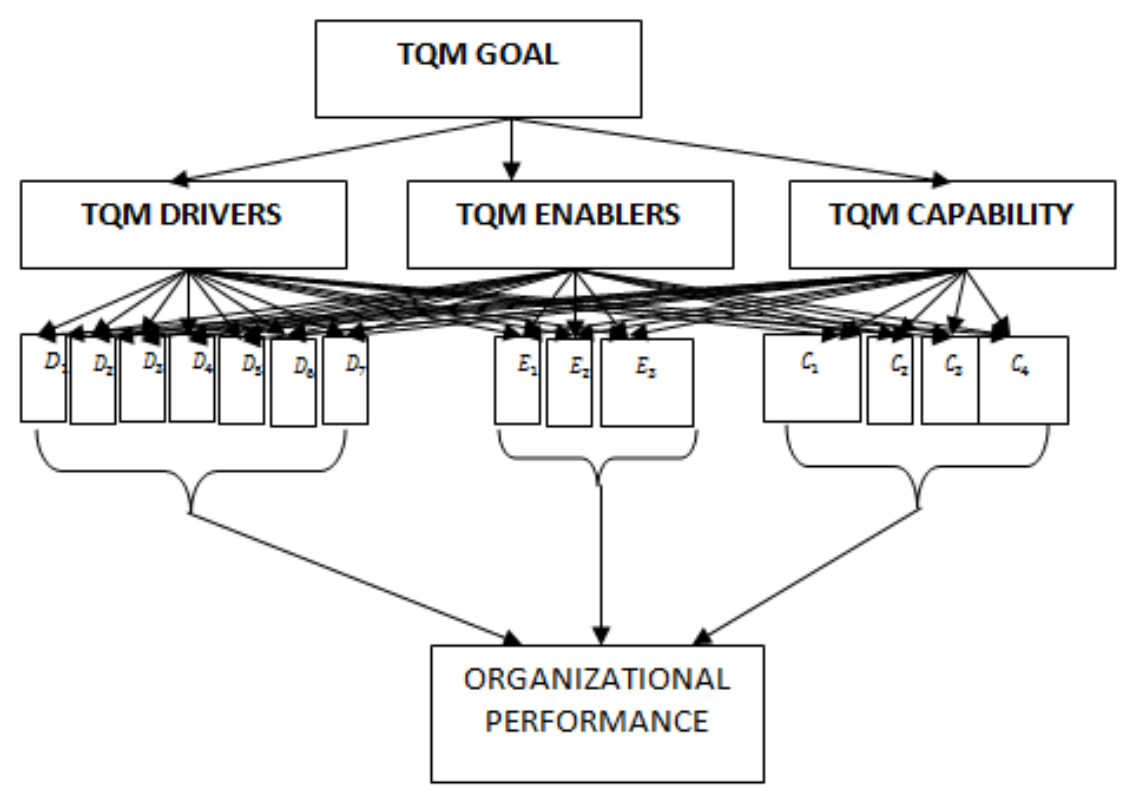

Figure 1 Hierarchy Based Performance Measurement Model

TQM Drivers: $D_{1}$-Top Level Management; $D_{2}$-Customer Focus/Customer Centricity; $D_{3^{-}}$Continuous improvement and innovation; $D_{4^{-}}$Supplier management; $D_{5}$-Employee involvement; $D_{6}$-Quality Information /Information Quality; $D_{7}$-Benchmarking

TQM Enablers: $E_{1^{-}}$Culture and communication; $\mathrm{E}_{2^{-}}$Employee encouragement and motivation; $E_{3^{-}}$Training and education

TQM Capability: $C_{1}$-Zero Defect; $C_{2}$-Waste Reduction; $C_{3^{-}}$Continuous Improvement Process; $C_{4}$-Performance Improvement

To implement the method, it was necessary the support of an expert in decision-making methods and of those engaged for TQM implementation in the FMCGs industry studied here. The support of the decision-making expert was necessary since he was responsible for telling the TQM staff how the judgments should be performed, how the program should be used and what maximum value should the inconsistency take. Experienced people were chosen from and formed three groups of evaluators. Table 2 presents the comparisons among TQM practices, provided by Group experts. The comparison matrix presented in Table 2 is consistent. Remarkably, all the comparison matrices provided by the Group experts were consistent. These are indications that the experts were aware about their judgement.

Table 2: Pair-Wise Comparison of the Three Main Criteria with Respect to the TQM Practices

\begin{tabular}{|l|c|c|c|c|}
\hline \multicolumn{1}{|c|}{ TQM Goal based on } & DRIVERS & ENABLERS & CAPABILLITIES & PRIORITY \\
\hline DRIVERS & 1 & 3 & 5 & $65.2 \%$ \\
\hline ENABLERS & $1 / 3$ & 1 & 2 & $22.3 \%$ \\
\hline CAPABILLITIES & $1 / 5$ & $1 / 2$ & 1 & $12.5 \%$ \\
\hline
\end{tabular}

The Aggregation of Individual Priorities (Saaty and Peniwati, 2007) was applied to aggregate their comparisons. The experts were considered as equally important. That is, their priorities had the same weight when aggregated.

Explanation of the attributes of TQM used is as: 
Oakland (1993) suggested ten basic steps in the implementation of TQM projects from that the extracted points which emphasizes critical success factors are as about: Develop the mission onto its critical success factors (CSFs) to coerce and move it forward, Breakdown the critical success factors into the key or critical process and gain process ownership as-well-as prepare project quality plans for all levels of work and Breakdown the critical success factors into sub-processes, activities and tasks and form improvement teams around these.

Top level management $\left(D_{l}\right)$ Top level management is the one, which is responsible for a firm's strategy, can also be judged how performance is scaled for improvement. The majority of respondents reported "the lack of complete top management commitment from the start, and through the process" to be the obvious barrier to TQM success. The achievement of organizational goals is based on top management teams' ability to anticipate and respond to external change (Burgelman, 1991; Child, 1972).W. C. Auden et al. (2006) emphasized as summary of the work that the top management team seems to have a strong influence on the firm's performance.

Customer focus/Customer Centricity $\left(D_{2}\right)$ Customer Focus involves researching what customers or end users want from products or services. Prajogo and Cooper (2010) argue that quality customer service is one of the most important aspects of TQM because in any customer-oriented business the customers are the organisation's main stakeholders. Nair (2006) highlighted the importance of customer focus by demonstrating evidence of a strong relationship between customer focus and firm performance. Moreover, customer focus receives attention as a CSF, because every effort of TQM is a customer orientated.

Continuous improvement and innovation $\left(D_{3}\right) \mathrm{TQM}$ practices enhance competitive performance by improving the quality of products and processes. The continuous improvement leads to dynamic outcomes of innovation, namely product innovation - changes in the specific products/services offered to the customers and process innovation - and changes in the mode by which the products are created or delivered. Innovation refers to an outcome perceived as new, regardless of whether it is an idea, object or process, as well as to the process of creating this newness (Slappendel, 1996).

Supplier's management $\left(D_{4}\right)$ supplier's management acts as an interface between TQM and Supply Chain Management (SCM). Managing the flow of goods between the manufacturer and customers is a fundamental part of organizations. To accomplish this the well-trained employees, ensure consistent, reliable and secure supply. Material traceability is always also maintained through robust quality management systems.Vanichchinchai, A. and Igel, B. (2011) investigated the relationships among total quality management practices (TQMP), supply chain management practices (SCMP) and firm's supply performance (FSP) in the automotive industry in Thailand and found that the set of SCMP, TQMP and FSP measures are reliable and valid. Gunasekaran and McGaughey (2003) earlier also suggested that TQM could play a key role in improving SCM.

Employee Involvement: $\left(D_{5}\right)$ The negative implications of TQM and performance management inconsistency is also compounded by the fact that employee's engagement in designing and implementing the performance management system, in the majority of organizations, is quite low. The survey on employee engagement reported in Gallup Management Journal (2002) according to the report (see, for further details, gmj.gallup.com), "more than half of the employees may not be engaged with their work". Involvement of employee automatically empowers the people to make decisions, make choices, take risks, and make new contributions. This congruity, in turn, will improve employee motivation and attitudes towards effective implementation of TQM initiatives. 
Quality Information/Information Quality $\left(D_{6}\right)$ To have an effective TQM implementation, organization must ensure that data are valid and reliable. They measure what they are supposed to consistently, and employees should have access to the data that are needed to carry out the tasks, Seetharaman, A. et al. (2006). Lakhal et al. (2006) establish through study and confirm the relevance of data-based factual decision-making by pointing out that information and analysis have a significant direct effect on various performance measures. Information and analysis and plant performance are correlated positively, years back shown by Choi and Eboch (1998) in their study.

Benchmarking $\left(D_{7}\right)$ Benchmarking aims to measure organization's operations or processes against the best-in-class performers from inside or outside its industry. The usefulness of benchmarking for improving the performance of the organization and to achieve competitive advantagehelp in continuous service improvements and establishment of customer satisfaction. Benchmarking can significantly affect the improvement of key business processes and consequently, increase the quality level, Hietschold, N. et al. (2014). Without benchmarking, organisations do not know their relative performance and they probably fail to design processes more effectively (Rao, S. et al. 1999).

Culture and communication $\left(E_{l}\right)$ : Competent organizational culture can be defined as, a set of congruent behaviors, attitudes, and policies that come together in a system, agency, or among professionals that enable them to work effectively in cross cultural situations.(Saldana, 2001). Culture is important to improve the communication among top-to bottom, bottom-to-top and across the departments, in which the information is shared by each staff. Antony, J. et al. (2002). As a concept, 'Quality' implies that an organization understands what customers require of a product or service, and is able not only to meet this requirement but can also exceed the expectations of the customer. This demands a particular culture that can in fact, be seen to be embedded in TQM philosophy, which embraces the idea of encouraging an organization to strive for continuous improvement in its values and methods of operation in order to achieve customer satisfaction.

Employee encouragement and motivation $\left(E_{2}\right)$ White and Nebeker (1996, p. 210) in their review of "reward and recognition and their functions in TQM organizations" point out that: A team-based perspective that focus on process improvement and personal development could improve effectiveness of performance appraisal as well as TQM objectives. Soltani, E. el al. (2005) survey indicated that their performance management systems in relation to having a positive impact on employee motivation towards successful implementation of quality programs were "very" and "moderately" effective.

Training and education $\left(\boldsymbol{E}_{3}\right)$ Mital et al. (1999) along with group of fifteenco-authors recommend that there is a dire need to train workers in manufacturing organizations and thereby improve the overall effectiveness and efficiency of such organizations. Further also mentioned that in order to compete successfully in the global market, manufacturing organizations must aim at training workers in skills necessary to produce quality goods. Strong correlation between quality performance and employee training is established in a study by Solis et al. (2000).

Zero-defect $\left(\boldsymbol{C}_{\boldsymbol{l}}\right)$ Zero Defects focuses on conditioning the employee to ensure a personal interest serves as motivation in everything they do. This is done by motivating the employee towards work importantly for the success of the organization. Specific goals, based on the customer's requirements (Linderman, K. et al., 2003) that are grounded on a philosophy of continuous improvements, all the points that combines TQM, Zero Defect Mindset (ZDM) and Six Sigma together. Total quality management models tend to incorporate the zero-defect vision by maximizing the overlap of customer demands and delivered product features, while costs have to be minimized, M. Colledani et al.(2014). 
Waste reduction $\left(C_{2}\right)$ The increase in lead-time also causes quality related phenomena which reduces the observability of the critical product quality feature in the system, further reduces the ability to detect a potentially generated defect within a short time. Colledani et al. (2014) stated that this directly translates into the propagation of more defects between the processing stages in the system and a waste of production capacity in processing parts that are already defective. A loss of capacity leads to a loss of total throughput.

Continuous improvement process $\left(C_{3}\right)$ Walsh, A. et al. (2002), outlook that many organizations show great enthusiasm for TQM during the initial year of TQM initiatives but then fall victim to a lackluster attitude towards its continuation. Lastly authors concluded with emphasizing that it is most important to remember that successful TQM strategies are based around the concept of continuous improvement. The continuous improvement of the process leads to customer satisfaction, which results in an external quality improvement. The continuous improvement also leads to fewer defects, which results in an internal quality improvement (Dahlgaard et al., 1994).

Performance improvement $\left(C_{4}\right)$ TQM is not limited to shop floor; it may be applied throughout the enterprise. This encompasses whole functions of the organization. TQM provides a single, unifying approach for the entire enterprise using performance improvement as the capability. This capability of TQM is important for organizations that offer highvariety and custom products today, but it will become increasingly important as we look to the future with mass customization.

To achieve the goal of the TQM through existing drivers, enablers and capabilities is shown in figure 1 with respective factors as sub-criteria. This work may be extended by considering the sub sub-criteria of each factor, which is not considered in this research.

\section{Performance Measurement Based on Fuzzy AHP Methodology}

After determining the evaluation criteria and the alternatives, the steps of the integrated fuzzy AHP algorithm are implemented. To obtain the importance of each factor first the experts utilised saaty's nine point scale, and result is obtained. Table 3 gives the results of the pair-wise comparisons of the evaluation criteria made by experts. Tables 2 and 3 , the aggregated fuzzy evaluation matrix for the criteria weights is obtained as in Table 4.

Table 3: Pair-Wise Comparison of Attributes of TQM

\begin{tabular}{|c|c|c|c|c|c|c|c|c|c|c|c|c|c|c|c|}
\hline \multirow{2}{*}{\multicolumn{2}{|c|}{ TQM }} & \multicolumn{7}{|c|}{ Drivers } & \multicolumn{3}{|c|}{ Enablers } & \multicolumn{4}{|c|}{ Capabilities } \\
\hline & & $D_{1}$ & $D_{2}$ & $D_{3}$ & $\mathrm{D}_{4}$ & $D_{5}$ & $D_{6}$ & $D_{7}$ & $E_{1}$ & $E_{2}$ & $E_{3}$ & $C_{1}$ & $C_{2}$ & $C_{3}$ & $C_{4}$ \\
\hline \multirow{7}{*}{ 党 } & $D_{1}$ & 1 & 9 & 5 & 7 & 3 & 7 & 5 & 4 & 4 & 6 & 4 & 5 & 5 & 7 \\
\hline & $\mathrm{D}_{2}$ & $1 / 9$ & 1 & 2 & 5 & 2 & 4 & 2 & 2 & 2 & 2 & 4 & 2 & 2 & 3 \\
\hline & $D_{3}$ & $1 / 5$ & $1 / 2$ & 1 & 2 & 3 & 7 & 4 & 7 & 5 & 3 & 8 & 8 & 9 & 5 \\
\hline & $D_{4}$ & $1 / 7$ & $1 / 5$ & $1 / 2$ & 1 & 2 & 8 & 2 & 3 & 3 & 2 & 6 & 5 & 4 & 5 \\
\hline & $D_{5}$ & $1 / 3$ & $1 / 2$ & $1 / 3$ & $1 / 2$ & 1 & 5 & 4 & 7 & 9 & 5 & 7 & 7 & 6 & 6 \\
\hline & $D_{6}$ & $1 / 7$ & $1 / 4$ & $1 / 7$ & $1 / 8$ & $1 / 5$ & 1 & 3 & 4 & 3 & 3 & 5 & 4 & 5 & 7 \\
\hline & $D_{7}$ & $1 / 5$ & $1 / 2$ & $1 / 4$ & $1 / 2$ & $1 / 4$ & $1 / 3$ & 1 & 3 & 3 & 2 & 4 & 4 & 4 & 6 \\
\hline \multirow{3}{*}{$\frac{\frac{2}{0}}{\frac{0}{0}}$} & $E_{1}$ & $1 / 4$ & $1 / 2$ & $1 / 7$ & $1 / 3$ & $1 / 7$ & $1 / 4$ & $1 / 3$ & 1 & 5 & 3 & 5 & 5 & 6 & 4 \\
\hline & $E_{2}$ & $1 / 4$ & $1 / 2$ & $1 / 5$ & $1 / 3$ & $1 / 9$ & $1 / 3$ & $1 / 3$ & $1 / 5$ & 1 & 3 & 5 & 5 & 7 & 5 \\
\hline & $E_{3}$ & $1 / 6$ & $1 / 2$ & $1 / 3$ & $1 / 2$ & $1 / 5$ & $1 / 3$ & $1 / 2$ & $1 / 3$ & $1 / 3$ & 1 & 3 & 3 & 5 & 5 \\
\hline \multirow{4}{*}{ 己ै } & $C_{I}$ & $1 / 4$ & $1 / 4$ & $1 / 8$ & $1 / 6$ & $1 / 7$ & $1 / 5$ & $1 / 4$ & $1 / 5$ & $1 / 5$ & $1 / 3$ & 1 & 9 & 7 & 9 \\
\hline & $C_{2}$ & $1 / 5$ & $1 / 2$ & $1 / 8$ & $1 / 5$ & $1 / 7$ & $1 / 4$ & $1 / 4$ & $1 / 5$ & $1 / 5$ & $1 / 3$ & $1 / 9$ & 1 & 5 & 7 \\
\hline & $C_{3}$ & $1 / 7$ & $1 / 3$ & $1 / 5$ & $1 / 5$ & $1 / 6$ & $1 / 7$ & $1 / 6$ & $1 / 4$ & $1 / 5$ & $1 / 5$ & $1 / 9$ & $1 / 7$ & 1 & 9 \\
\hline & $C_{4}$ & $1 / 7$ & $1 / 3$ & $1 / 5$ & $1 / 5$ & $1 / 6$ & $1 / 7$ & $1 / 6$ & $1 / 4$ & $1 / 5$ & $1 / 5$ & $1 / 9$ & $1 / 7$ & $1 / 9$ & 1 \\
\hline
\end{tabular}


For pairwise comparisons of criteria and alternatives, Saaty (1994) defined a scale of integers from 1 to 9 that express how many times more important or dominant one attribute is over another one. To each number from the scale assigned a linguistic term describing the intensity of importance or dominance of one attribute over another. Generally, integers 1, 3, 5, 7 and 9 are used for making pair wise comparisons of attributes. In case where more detailed comparisons are desirable then intermediate values $2,4,6$, and 8 is selected. A square pair wise comparison matrix $A=\left[\alpha_{i j}\right]_{i j=1}^{p}$ is constructed ( $p=14$ in our case) , Table 3. An element $a_{i j}$ expresses how many times more important $x_{i}$ is over $x_{j}$ with respect to a particular object from the upper level of the hierarchy. It is obvious that $a_{i i}=1, i=1, \ldots, p$, as we compare $x_{i}$ with itself. Further, when object $x_{i}$ is $a_{i j}$ times more important than object $x_{j}$, then obviously object $x_{j}$ takes only the $1 / a_{i j}$-th of the importance of object $x_{i}$. Therefore, the pairwise comparison matrix $A=\left[a_{i j}\right]_{i j=1}^{p}$ is reciprocal, i.e. $a_{j i}=1 / a_{i j}$ for all $i, j \in\{1, \ldots, p\}$

As this work is carried in an Indian FMCGs industry, so in real-world decision- making problems, the information provided by decision makers is often vague because the information is given by means of linguistically. Thus, fuzzy AHP has been developed in order to deal with vagueness and imprecision. Many different approaches to the fuzzification of Saaty's scale have been proposed in the literature. The authors expressed the meaning of the linguistic terms by triangular fuzzy numbers.

Using the elements from a considered fuzzified scale, a fuzzy pairwise comparison matrix $A=\left[\alpha_{i j j}\right]_{i j=1}^{p}$ is constructed (Table 4), i.e. $\tilde{\alpha}_{i j}=\mathbb{1}^{\sim}, i=1, \ldots, p$, and $\tilde{\alpha}_{j i}=1 / \tilde{\alpha}_{i j}$ for alli,je $\{1, \ldots, p\}$.

Table 4: With Fuzzy Numbers

\begin{tabular}{|c|c|c|c|c|c|c|c|c|c|c|c|c|c|c|c|}
\hline \multirow{2}{*}{\multicolumn{2}{|c|}{ TQM }} & \multicolumn{7}{|c|}{ Drivers } & \multicolumn{4}{|c|}{ Enablers } & \multicolumn{3}{|c|}{ Capabilities } \\
\hline & & $\mathrm{D}_{1}$ & $\mathrm{D}_{2}$ & $\mathbf{D}_{3}$ & $\mathrm{D}_{4}$ & $D_{5}$ & $D_{6}$ & $D_{7}$ & $E_{1}$ & $\mathbf{E}_{2}$ & $\mathbf{E}_{3}$ & $\mathrm{C}_{1}$ & $\mathrm{C}_{2}$ & $\mathrm{C}_{3}$ & $\mathrm{C}_{4}$ \\
\hline \multirow{7}{*}{ 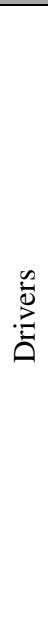 } & D & $1,1,1$ & $9,9,9$ & $4,5,6$ & $6,7,8$ & $2,3,4$ & $6,7,8$ & $4,5,6$ & $3,4,5$ & $3,4,5$ & $5,6,7$ & $3,4,5$ & $4,5,6$ & $4,5,6$ & $6,7,8$ \\
\hline & D & $\begin{array}{l}1 / 9,1 / \\
9,1 / 9\end{array}$ & $1,1,1$ & $1,2,3$ & $4,5,6$ & $1,2,3$ & $3,4,5$ & $1,2,3$ & $1,2,3$ & $1,2,3$ & $1,2,3$ & $3,4,5$ & $1,2,3$ & $1,2,3$ & $2,3,4$ \\
\hline & $\begin{array}{l}\text { D } \\
3\end{array}$ & $\begin{array}{l}1 / 6,1 / \\
5,1 / 4\end{array}$ & $\begin{array}{c}1 / 3,1 \\
/ 2,1 \\
\end{array}$ & $1,1,1$ & $1,2,3$ & $2,3,4$ & $6,7,8$ & $3,4,5$ & $6,7,8$ & $4,5,6$ & $2,3,4$ & $7,8,9$ & $7,8,9$ & $9,9,9$ & $4,5,6$ \\
\hline & $\begin{array}{c}\text { D } \\
4\end{array}$ & $\begin{array}{l}1 / 8,1 / \\
7,1 / 6\end{array}$ & $\begin{array}{c}1 / 6,1 \\
/ 5,1 / \\
4\end{array}$ & $\begin{array}{c}1 / 3,1 / \\
2,1\end{array}$ & $1,1,1$ & $1,2,3$ & $7,8,9$ & $1,2,3$ & $2,3,4$ & $2,3,4$ & $1,2,3$ & $5,6,7$ & $4,5,6$ & $3,4,5$ & $4,5,6$ \\
\hline & $\begin{array}{l}\text { D } \\
5 \\
\end{array}$ & $\begin{array}{l}1 / 4,1 / \\
3,1 / 2 \\
\end{array}$ & $\begin{array}{l}1 / 3,1 \\
2,1 \\
\end{array}$ & $\begin{array}{l}1 / 4,1 / \\
3,1 / 2 \\
\end{array}$ & $\begin{array}{c}1 / 3,1 / \\
2,1 \\
\end{array}$ & $1,1,1$ & $4,5,6$ & $3,4,5$ & $6,7,8$ & $9,9,9$ & $4,5,6$ & $6,7,8$ & $6,7,8$ & $5,6,7$ & $5,6,7$ \\
\hline & $\begin{array}{c}\text { D } \\
6\end{array}$ & $\begin{array}{l}1 / 8,1 / \\
7,1 / 6\end{array}$ & $\begin{array}{c}1 / 5,1 \\
/ 4,3 / \\
4\end{array}$ & $\begin{array}{l}1 / 8,1 / \\
7,1 / 6\end{array}$ & $\begin{array}{l}1 / 9,1 / \\
8,1 / 7\end{array}$ & $\begin{array}{c}1 / 6,1 \\
/ 5,1 / \\
4\end{array}$ & $1,1,1$ & $2,3,4$ & $3,4,5$ & $2,3,4$ & $2,3,4$ & $4,5,6$ & $3,4,5$ & $4,5,6$ & $6,7,8$ \\
\hline & $\begin{array}{c}\text { D } \\
7\end{array}$ & $\begin{array}{l}1 / 6,1 / \\
5,1 / 4\end{array}$ & $\begin{array}{c}1 / 3,1 \\
/ 2,1\end{array}$ & $\begin{array}{l}1 / 5,1 / \\
4,3 / 4\end{array}$ & $\begin{array}{c}1 / 3,1 / \\
2,1\end{array}$ & $\begin{array}{c}1 / 5,1 \\
/ 4,3 / \\
4 \\
\end{array}$ & $\begin{array}{c}1 / 4,1 \\
/ 3,1 / \\
2 \\
\end{array}$ & $1,1,1$ & $2,3,4$ & $2,3,4$ & $1,2,3$ & $3,4,5$ & $3,4,5$ & $3,4,5$ & $5,6,7$ \\
\hline \multirow{3}{*}{ 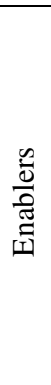 } & $\begin{array}{c}E \\
1\end{array}$ & $\begin{array}{l}1 / 5,1 / \\
4,3 / 4\end{array}$ & $\begin{array}{c}1 / 3,1 \\
/ 2,1\end{array}$ & $\begin{array}{l}1 / 8,1 / \\
7,1 / 6\end{array}$ & $\begin{array}{l}1 / 4,1 / \\
3,1 / 2\end{array}$ & $\begin{array}{c}1 / 8,1 \\
/ 7,1 / \\
6\end{array}$ & $\begin{array}{c}1 / 5,1 \\
/ 4,1 / \\
3\end{array}$ & $\begin{array}{c}1 / 4,1 \\
13,1 / \\
2\end{array}$ & $1,1,1$ & $4,5,6$ & $2,3,4$ & $4,5,6$ & $4,5,6$ & $5,6,7$ & $3,4,5$ \\
\hline & $\begin{array}{c}\mathbf{E} \\
2\end{array}$ & $\begin{array}{l}1 / 5,1 / \\
4,3 / 4\end{array}$ & $\begin{array}{c}1 / 3,1 \\
/ 2,1\end{array}$ & $\begin{array}{l}1 / 6,1 / \\
5,1 / 4\end{array}$ & $\begin{array}{l}1 / 4,1 / \\
3,1 / 2\end{array}$ & $\begin{array}{c}1 / 9,1 \\
19,1 / \\
9\end{array}$ & $\begin{array}{c}1 / 4,1 \\
13,1 / \\
2\end{array}$ & $\begin{array}{c}1 / 4,1 \\
/ 3,1 / \\
2\end{array}$ & $\begin{array}{c}1 / 6,1 \\
/ 5,1 / \\
4\end{array}$ & $1,1,1$ & $2,3,4$ & $4,5,6$ & $4,5,6$ & $6,7,8$ & $4,5,6$ \\
\hline & $\begin{array}{c}\mathbf{E} \\
3\end{array}$ & $\begin{array}{l}1 / 7,1 / \\
6,1 / 5\end{array}$ & $\begin{array}{c}1 / 3,1 \\
/ 2,1\end{array}$ & $\begin{array}{l}1 / 4,1 / \\
3,1 / 2\end{array}$ & $\begin{array}{c}1 / 3,1 / \\
2,1\end{array}$ & $\begin{array}{c}1 / 6,1 \\
/ 5,1 / \\
4\end{array}$ & $\begin{array}{c}1 / 4,1 \\
13,1 / \\
2\end{array}$ & $\begin{array}{c}1 / 3,1 \\
/ 2,1\end{array}$ & $\begin{array}{c}1 / 4,1 \\
/ 3,1 / \\
2\end{array}$ & $\begin{array}{c}1 / 4,1 \\
13,1 / \\
2\end{array}$ & $1,1,1$ & $2,3,4$ & $2,3,4$ & $4,5,6$ & $4,5,6$ \\
\hline
\end{tabular}




\begin{tabular}{|c|c|c|c|c|c|c|c|c|c|c|c|c|c|c|c|}
\hline \multirow{4}{*}{ 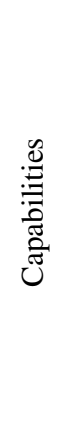 } & $\begin{array}{l}\text { C } \\
1\end{array}$ & $\begin{array}{l}1 / 5,1 / \\
4,3 / 4\end{array}$ & $\begin{array}{c}1 / 5,1 \\
/ 4,3 / \\
4\end{array}$ & $\begin{array}{l}1 / 9,1 / \\
8,1 / 7\end{array}$ & $\begin{array}{l}1 / 7,1 / \\
6,1 / 5\end{array}$ & $\begin{array}{c}1 / 8,1 \\
/ 7,1 / \\
6\end{array}$ & $\begin{array}{c}1 / 6,1 \\
/ 5,1 / \\
4\end{array}$ & $\begin{array}{c}1 / 5,1 \\
/ 4,3 / \\
4\end{array}$ & $\begin{array}{c}1 / 6,1 \\
/ 5,1 / \\
4\end{array}$ & $\begin{array}{c}1 / 6,1 \\
/ 5,1 / \\
4\end{array}$ & $\begin{array}{c}1 / 4,1 \\
/ 3,1 / \\
2\end{array}$ & $\mathbf{1 , 1 , 1}$ & $9,9,9$ & $6,7,8$ & $9,9,9$ \\
\hline & $\begin{array}{l}\mathrm{C} \\
2\end{array}$ & $\begin{array}{l}1 / 6,1 / \\
5,1 / 4\end{array}$ & $\begin{array}{c}1 / 3,1 \\
/ 2,1\end{array}$ & $\begin{array}{l}1 / 9,1 / \\
8,1 / 7\end{array}$ & $\begin{array}{l}1 / 6,1 / \\
5,1 / 4\end{array}$ & $\begin{array}{c}1 / 8,1 \\
/ 7,1 / \\
6\end{array}$ & $\begin{array}{c}1 / 5,1 \\
/ 4,3 / \\
4\end{array}$ & $\begin{array}{c}1 / 5,1 \\
/ 4,3 / \\
4\end{array}$ & $\begin{array}{c}1 / 6,1 \\
15,1 / \\
4\end{array}$ & $\begin{array}{c}1 / 6,1 \\
15,1 / \\
4\end{array}$ & $\begin{array}{c}1 / 4,1 \\
/ 3,1 / \\
2\end{array}$ & $\begin{array}{c}1 / 9,1 \\
/ 9,1 / \\
9\end{array}$ & $1,1,1$ & $4,5,6$ & $6,7,8$ \\
\hline & $\begin{array}{l}\mathrm{C} \\
3\end{array}$ & $\begin{array}{l}1 / 8,1 / \\
7,1 / 6\end{array}$ & $\begin{array}{c}1 / 4,1 \\
13,1 / \\
2\end{array}$ & $\begin{array}{l}1 / 6,1 / \\
5,1 / 4\end{array}$ & $\begin{array}{l}1 / 6,1 / \\
5,1 / 4\end{array}$ & $\begin{array}{c}1 / 7,1 \\
/ 6,1 / \\
5\end{array}$ & $\begin{array}{c}1 / 8,1 \\
/ 7,1 / \\
6\end{array}$ & $\begin{array}{c}1 / 7,1 \\
/ 6,1 / \\
5\end{array}$ & $\begin{array}{c}1 / 5,1 \\
/ 4,3 / \\
4\end{array}$ & $\begin{array}{c}1 / 6,1 \\
15,1 / \\
4\end{array}$ & $\begin{array}{c}1 / 6,1 \\
15,1 / \\
4\end{array}$ & $\begin{array}{c}1 / 9,1 \\
/ 9,1 / \\
9\end{array}$ & $\begin{array}{c}1 / 8,1 \\
/ 7,1 / \\
6\end{array}$ & $1,1,1$ & $9,9,9$ \\
\hline & $\begin{array}{l}\text { C } \\
4\end{array}$ & $\begin{array}{l}1 / 8,1 / \\
7,1 / 6\end{array}$ & $\begin{array}{c}1 / 4,1 \\
13,1 / \\
2\end{array}$ & $\begin{array}{l}1 / 6,1 / \\
5,1 / 4\end{array}$ & $\begin{array}{l}1 / 6,1 / \\
5,1 / 4\end{array}$ & $\begin{array}{c}1 / 7,1 \\
/ 6,1 / \\
5\end{array}$ & $\begin{array}{c}1 / 8,1 \\
/ 7,1 / \\
6\end{array}$ & $\begin{array}{c}1 / 7,1 \\
/ 6,1 / \\
5\end{array}$ & $\begin{array}{c}1 / 5,1 \\
/ 4,3 / \\
4\end{array}$ & $\begin{array}{c}1 / 6,1 \\
/ 5,1 / \\
4\end{array}$ & $\begin{array}{c}1 / 6,1 \\
/ 5,1 / \\
4\end{array}$ & $\begin{array}{c}1 / 9,1 \\
/ 9,1 / \\
9\end{array}$ & $\begin{array}{c}1 / 8,1 \\
/ 7,1 / \\
6\end{array}$ & $\begin{array}{c}1 / 9,1 \\
19,1 / \\
9\end{array}$ & $1,1,1$ \\
\hline
\end{tabular}

For $i=j$, there is obviously no fuzziness in the comparison, and thus, $\mathbb{a}_{j i}$ has to be set as $(1,1,1)$ for any $i \in\{1, \ldots$ ,$p$. On the other hand, when two different attributes $x_{i}$ and $x_{j}, i=j$, are assessed to be "equally important", then this comparison may contain some fuzziness.

K Teknomo,(2006) suggested that in practice, don't need measurement of inconsistency Random Index (RI) for more than $n=7$ because the number of pair comparisons $n *(n-1) / 2$ become so large. Too many questions on the same things make people confuse to answer them correctly. Utilize the hierarchy by grouping some criteria into a higher level hierarchy of the criteria. As in this present study number of attributes considered by authors is 14 , which is more than 7 , so random indexing is exempted.

When the pairwise comparison matrix of objects is constructed, weights of the factors can be computed from the matrix. Based on Buckley's (1985) method, the geometric mean (Table 5) of fuzzy comparison value of every attribute in computed and formulated in equation below. This method is used because it is easy to extend to the fuzzy case and guarantees a unique solution to the reciprocal comparison matrix. The weight assessing method by geometric mean is chosen for its simplicity and ease in its application to the fuzzy case, Kaya, T., and Kahraman, C. (2011).

Formula used to obtain Fuzzy Geometric Mean Value of each attribute is calculated as

$$
\begin{aligned}
& \tilde{A}_{1} \otimes \tilde{A}_{2}=\left(\ell_{1}, m_{1}, u_{1}\right) \otimes\left(\ell_{2}, m_{2}, u_{2}\right) \\
& =\left(\ell_{1}+\ell_{2}, m_{1}+m_{2}, u_{1}+u_{2}\right)
\end{aligned}
$$

Table 5: Fuzzy Geometric Mean

\begin{tabular}{|l|c|c|c|c|}
\hline & \multicolumn{4}{|c|}{ Fuzzy Geometric Mean values } \\
\hline & $\mathbf{l}$ & $\mathbf{~}$ & $\mathbf{u}$ & \\
\hline $\mathrm{D}_{1}$ & 3.807 & 4.652 & 5.460 & $3.807,4.652,5.460$ \\
\hline $\mathrm{D}_{2}$ & 1.160 & 1.879 & 2.529 & $1.160,1.879,2.529$ \\
\hline $\mathrm{D}_{3}$ & 2.363 & 3.013 & 3.730 & $2.363,3.013,3.730$ \\
\hline $\mathrm{D}_{4}$ & 1.316 & 1.836 & 2.395 & $1.316,1.836,2.395$ \\
\hline $\mathrm{D}_{5}$ & 1.998 & 2.467 & 3.166 & $1.998,2.467,3.166$ \\
\hline $\mathrm{D}_{6}$ & 0.937 & 1.176 & 1.432 & $0.937,1.176,1.432$ \\
\hline $\mathrm{D}_{7}$ & 0.848 & 1.151 & 1.576 & $0.848,1.151,1.576$ \\
\hline $\mathrm{E}_{1}$ & 0.768 & 0.968 & 1.252 & $0.768,0.968,1.252$ \\
\hline $\mathrm{E}_{2}$ & 0.651 & 0.812 & 1.051 & $0.651,0.8112,1.051$ \\
\hline $\mathrm{E}_{3}$ & 0.548 & 0.727 & 1.043 & $0.548,0.727,1.043$ \\
\hline $\mathrm{C}_{1}$ & 0.436 & 0.505 & 0.606 & $0.436,0.505,0.606$ \\
\hline $\mathrm{C}_{2}$ & 0.315 & 0.377 & 0.472 & $0.315,0.377,0.472$ \\
\hline $\mathrm{C}_{3}$ & 0.235 & 0.270 & 0.320 & $0.235,0.270,0.320$ \\
\hline $\mathrm{C}_{4}$ & 0.171 & 0.197 & 0.234 & $0.171,0.197,0.234$ \\
\hline
\end{tabular}


Then Fuzzy weight is calculated of each attribute using formula

$$
\begin{array}{r}
\tilde{W}_{\mathrm{i}=} \tilde{r}_{1} \otimes\left(\tilde{r}_{1} \oplus \tilde{r}_{2} \ldots \ldots \ldots . . . \oplus \tilde{r}_{n}\right)^{-1} \text { Also, } \tilde{A}_{1} \oplus \tilde{A}_{2}=\left(\ell_{1}, m_{1}, u_{1}\right) \oplus\left(\ell_{2}, m_{2}, u_{2}\right) \\
=\left(\ell_{1}+\ell_{2}, m_{1+} m_{2}, u_{1}+u_{2}\right)
\end{array}
$$

Table 6: Fuzzy Weights

\begin{tabular}{|c|c|c|c|c|}
\hline & \multicolumn{4}{|c|}{ Fuzzy Weights } \\
\hline & $\mathbf{l}$ & $\mathbf{m}$ & $\mathbf{u}$ & \\
\hline $\mathrm{D}_{1}$ & 0.151 & 0.232 & 0.351 & $0.151,0.232,0.351$ \\
\hline $\mathrm{D}_{2}$ & 0.046 & 0.094 & 0.163 & $0.046,0.094,0.163$ \\
\hline $\mathrm{D}_{3}$ & 0.094 & 0.150 & 0.240 & $0.094,0.150,0.240$ \\
\hline $\mathrm{D}_{4}$ & 0.052 & 0.092 & 0.154 & $0.052,0.092,0.154$ \\
\hline $\mathrm{D}_{5}$ & 0.079 & 0.123 & 0.204 & $0.079,0.123,0.204$ \\
\hline $\mathrm{D}_{6}$ & 0.037 & 0.059 & 0.092 & $0.037,0.059,0.092$ \\
\hline $\mathrm{D}_{7}$ & 0.034 & 0.057 & 0.101 & $0.034,0.057,0.101$ \\
\hline $\mathrm{E}_{1}$ & 0.030 & 0.048 & 0.081 & $0.030,0.048,0.081$ \\
\hline $\mathrm{E}_{2}$ & 0.026 & 0.041 & 0.068 & $0.026,0.041,0.068$ \\
\hline $\mathrm{E}_{3}$ & 0.022 & 0.036 & 0.067 & $0.022,0.036,0.067$ \\
\hline $\mathrm{C}_{1}$ & 0.017 & 0.025 & 0.039 & $0.017,0.025,0.039$ \\
\hline $\mathrm{C}_{2}$ & 0.012 & 0.019 & 0.030 & $0.012,0.019,0.030$ \\
\hline $\mathrm{C}_{3}$ & 0.009 & 0.013 & 0.021 & $0.009,0.013,0.021$ \\
\hline $\mathrm{C}_{4}$ & 0.007 & 0.010 & 0.015 & $0.007,0.010,0.015$ \\
\hline
\end{tabular}

Fuzzy weights are defuzzified using Centre of area (COA) method to get the crisp values for all the factors considered for the study and then normalised. The value obtained $\mathrm{w}_{\text {total }}>1$, so it must be normalised. On the basis of the normalised values the ranking of TQM attributes demonstrated that impact on its performance. It is observed that Top level management $\left(D_{1}\right)$ is given the highest ranking for these factors with normalised weight $(0.180)$. The rankings of collected factors for each category aggregately are computed in a similar manner.

\begin{tabular}{|c|c|c|c|c|}
\hline & \multirow{2}{*}{$\begin{array}{l}\text { De-fuzzified weights } \\
\text { using centroid method }\end{array}$} & \multirow{2}{*}{$\begin{array}{c}\begin{array}{c}\text { normalised } \\
\text { weights }\end{array} \\
\frac{m_{i}}{n_{i} B_{i}}\end{array}$} & \multirow[t]{2}{*}{ Ranking } \\
\hline & & & & \\
\hline $\mathrm{D}_{1}$ & $0.151,0.232,0.351$ & 0.244646176 & 0.180 & 1 \\
\hline $\mathrm{D}_{2}$ & $0.046,0.094,0.163$ & 0.100766316 & 0.079 & 4 \\
\hline $\mathrm{D}_{3}$ & $0.094,0.150,0.240$ & 0.161247026 & 0.120 & 2 \\
\hline $\mathrm{D}_{4}$ & $0.052,0.092,0.154$ & 0.099234373 & 0.076 & 5 \\
\hline $\mathrm{D}_{5}$ & $0.079,0.123,0.204$ & 0.135261797 & 0.101 & 3 \\
\hline $\mathrm{D}_{6}$ & $0.037,0.059,0.092$ & 0.062610712 & 0.047 & 7 \\
\hline $\mathrm{D}_{7}$ & $0.034,0.057,0.101$ & 0.064129672 & 0.049 & 6 \\
\hline$E_{1}$ & $0.030,0.048,0.081$ & 0.053090707 & 0.040 & 8 \\
\hline $\mathrm{E}_{2}$ & $0.026,0.041,0.068$ & 0.044620883 & 0.033 & 9 \\
\hline $\mathrm{E}_{3}$ & $0.022,0.036,0.067$ & 0.041682472 & 0.032 & 10 \\
\hline $\mathrm{C}_{1}$ & $0.017,0.025,0.039$ & 0.027134575 & 0.020 & 11 \\
\hline $\mathrm{C}_{2}$ & $0.012,0.019,0.030$ & 0.020549803 & 0.015 & 12 \\
\hline $\mathrm{C}_{3}$ & $0.009,0.013,0.021$ & 0.014453461 & 0.011 & 13 \\
\hline \begin{tabular}{l|l} 
& $\mathrm{C}_{4}$ \\
\end{tabular} & $0.007,0.010,0.015$ & 0.010559698 & 0.008 & 14 \\
\hline \multicolumn{2}{|c|}{ Total of De-fuzzified weights, $\mathrm{w}_{\text {total }}$} & 1.079987671 & & \\
\hline
\end{tabular}

Table 7: Priority Weights of Alternatives 
For interpretation of the result the rank is considered and termed them that they are acting as barriers to the TQM and must be take care of. As Performance improvement $\left(\mathrm{C}_{4}\right)$ is measured $14^{\text {th }}$ rank, is the most potential barrier identified.

In this way, the proposed performance model/framework is for the implemented TQM process, is evolvable, perfective or preventive changes may be introduced when needed, is specific for target FMCGs, more CSFs have been involved at different levels and has been evaluated mathematically, and then validated appropriately.

\section{MANAGERIAL IMPLICATION AND CONCLUSION}

In this practical work integrated FAH approach is proposed for solving a complex decision-making task related to TQM. To validate the potentiality of our approach we have analysed the implemented TQM of FMCGs industry. In the published research work, FAHP, based on the extent analysis method was used to derive the relative importance between the critical success factors and organisational performance. We have used the same pairwise comparison matrix as given in this original work and have utilized Buckley's FAHP approach (geometric mean approach) to calculate the relative importance among the risk factors. In the next task, to rank the attributes, we have proposed the normalization formulae to calculate the rank in practical manner. We believe that our approach is computationally faster, more accurate and requires less computational steps than the other performance assessment method. Although we have not compared our ranking result with any other work of the FAHP. Apart from that, when the number of critical success factors and alternatives are increased, our approach is sufficient to handle that situation and still provides credible ranking results. Next, we have proposed a quite simpler to interpret and is derived from simpler human reasoning. This integrated approach is believed to be a feasible choice among the performance measurement in industries to support the performance assessment task of other incorporated sub-systems like SCM, Six-Sigma, JIT, TPM etc. Apart from that, other weight calculation approaches may be use to improve the decision-making process.

Funding: This research did not receive any specific grant from agencies in the public, commercial, or not-forprofit sectors.

\section{Declarations of Interest: None}

\section{REFERENCES}

1. Ahire, S. L., Waller, M. A. \& Golhar, D. Y. (1996). Quality management in TQM versus non-TQM firms: an empirical investigation. International Journal of Quality 13(8): 8-27.

2. Auden, W. C., Shackman, J. D., \& Onken, M. H. (2006). Top management team, international risk management factor and firm performance. Team Performance Management: An International Journal, 12(7/8), 209224. doi:10.1108/13527590610711778

3. Anu P. Anil, Dr. Satish K. P. (2015), “Investigating the relationship between TQM practices and Firm's performance: A conceptual framework for Indian organizations", International Conference on Emerging Trends in Engineering, Science and Technology (ICETEST - 2015), Procedia Technology 24 ( 2016 ) 554 - 561, doi: 10.1016/j.protcy.2016.05.103

4. Antony, J., Leung, K., Knowles, G., \& Gosh, S. (2002). Critical success factors of TQM implementation in Hong Kong industries. International Journal of Quality \& Reliability Management, 19(5), 551-566. doi:10.1108/02656710210427520

5. Barot, Digvijay., et al. "An empirical assessment of smart phone usage amongst students and professors." International Journal of Business and General Management (IJBGM) 3 (2014): 19-28. 
6. Buckley, J. J. (1985) extended Saaty's AHP method to incorporate fuzzy comparison ratios aij and uses the geometric mean method to derive fuzzy weights and performance scores.

7. Buckley, J. J. (1985). Fuzzy hierarchical analysis. Fuzzy Sets and Systems, 17(2), 233-247. https://doi.org/10.1016/01650114(85)90090-9

8. Bellman, R. E., \& Zadeh, L. A. (1970). Decision-making in a fuzzy environment. Management Science, 17(4), 141-164.

9. Bratton, J. and J. Gold (1999). Human Resource Management: Theory and Practice (2nd edn). Macmillan Press, London.

10. Burgelman, R. (1991), "Intra-organizational ecology of strategy making and organizational adaptation: theory and field research”, Organization Science, Vol. 2, pp. 239-62.

11. Child, J. (1972), "Organization structure, environment, and performance: the role of strategic choice", Journal of Management Studies, Vol. 11, pp. 13-27.

12. Cheng, E.W.L and Li,H. (2002), "Analytic hierarchy process: a decision making method for construction management", Proceedings of the first International conference on construction in the 21st century (CITC2002), Challenges and opportunities in the Management and Technology, 25-26 April, Miami,FL

13. Chou TY, Hsu CL, Chen MC (2008) A fuzzy multi-criteria decision model for international tourist hotels location selection. Int J Hosp Manag 27(2):293-301

14. Choi, Thomas Y., and Karen Eboch. 1998. "The TQM Paradox: Relations among TQM Practices, Plant Performance, and Customer Satisfaction.” Journal of Operations Management 17 (1): 59-75.

15. Colledani, M., Tolio, T., Fischer, A., Iung, B., Lanza, G., Schmitt, R., \& Váncza, J. (2014). Design and management of manufacturing systems for production quality. CIRP Annals, 63(2), 773-796. doi:10.1016/j.cirp.2014.05.002

16. Dessler, G. (2000). Human resource management (8th ed.). New Jersey: Prentice-Hall.

17. Dess, G. G., \& Robinson, R. B. (1984). Measuring organizational performance in the absence of objective measures: The case of the privately-held firm and conglomerate business unit. Strategic Management Journal, 5(3), 265273. doi:10.1002/smj.4250050306

18. Demirbag, M., Tatoglu, E., Tekinkus, M. and Zaim, S. (2006), "An analysis of the relationship between TQM implementation and organizational performance: evidence from Turkish SMEs", Journal of Manufacturing Technology Management, Vol. 17 No. 6, pp. 829-47.

19. Dahlgaard, J.J., Kristensen, K. and Kanji, G.K. (1994), The Quality Journey: A Journey Without an End, Carfax, Arbingdon.

20. Eisenhardt, K.M., Kahwajy, J. and Bourgeois, L. (1998), "Conflict and strategic choice: how top management teams disagree”, in Hambrick, D., Nadler, D. and Tushman, M. (Eds), Navigating Change: How CEOs, Top Teams, and Boards Steer Transformation, Harvard Business School Press, Boston, MA.

21. Feigenbaum, A.V. (1988) Total quality control: achieving productivity, market penetration and advantage in the global economy, McGraw-Hill Higher Education.

22. Gallup Management Journal (2002), “Start worrying about "not engaged” employees”, Gallup Management Journal, available at: http://gmi.gallup.com.

23. Gunasekaran, A. and McGaughey, R.E., 2003. TQM in supply chain management. The TQM Magazine, 15 (6), $361-363$. 
24. Huang, L-C and Wu, R. Y-H. Applying fuzzy analytic hierarchy process in the managerial talent assessment model - an empirical study in Taiwan's semiconductor industry. Intern. Journal of Technology Management, Vol 30, No. 1/2. 2005. pp 105-130.

25. Hietschold, N., Reinhardt, R., \& Gurtner, S. (2014). Measuring critical success factors of TQM implementation successfullya systematic literature review. International Journal of Production

26. Ismail Salaheldin, S. (2009). Critical success factors for TQM implementation and their impact on performance of SMEs. International Journal of Productivity and Performance Management, 58(3), 215-237. doi:10.1108/17410400910938832

27. Jiansheng Zhangab and Wei Tana (2012)," Research on the Performance Evaluation of Logistics Enterprise Based on the Analytic Hierarchy Process", International Conference on Advances in Energy Engineering, Energy Procedia 14 (2012) 1618 $-1623$

28. Kayakutlu G, Buyukozkan $G$ (2011) Assessing performance factors for a 3PL in a value chain. International Journal of Production Economics, 131(2):441-452

29. Koh, S., Demirbag, M., Bayraktar, E., Tatoglu, E. and Zaim, S. (2007), "The impact of supply chain management practices on performance of SMEs”, Industrial Management \& Data Systems, Vol. 107 No. 1, pp. 103-24.

30. K Teknomo, “Analytic hierarchy process (AHP) tutorial”, Revoledu. com, 2006

31. Kaya, T., \&Kahraman, C. (2011). An integrated fuzzy AHP-ELECTRE methodology for environmental impact assessment. Expert Systems with Applications, 38(7), 8553-8562.

32. Kabir, G.; Akhtar Hasin, M.A. Multi-criteria inventory classification through integration of fuzzy analytic hierarchy process and artificial neural network. Int. J. Ind. Syst. Eng. 2013, 14, 74-103.

33. Kumar, P., \& Singh, R. K. (2012). A fuzzy AHP and TOPSIS methodology to evaluate 3PL in a supply chain. Journal of Modelling in Management, 7(3), 287-303. doi:10.1108/17465661211283287

34. Liou, James J.H., Tzeng, G.H., 2007. A non-additive model for evaluating airline service quality. Journal of Air Transport Management 13 (3), 131-138.

35. Li, Wenhua \& Yu, Suihuai \& Pei, Huining \& Zhao, Chuan \& Tian, Baozhen, 2017. "A hybrid approach based on fuzzy AHP and 2-tuple fuzzy linguistic method for evaluation in-flight service quality," Journal of Air Transport Management, Elsevier, vol. 60(C), pages 49-64. DOI: 10.1016/j.jairtraman.2017.01.006

36. Linderman, K., Schroeder, R. G., Zaheer, S. \& Choo, A. S., 2003. Six Sigma: a goal-theoretic perspective. Journal of Operational Management 21(2003), 21(2003), pp. 193-203.

37. Lakhal, Lassâad, Federico Pasin, and Mohamed Limam. 2006. "Quality Management Practices and their Impact on Performance." International Journal of Quality \& Reliability Management 23 (6): 625-646.

38. Motwani, J.G., Mahmoud, E. and Rice, G. (1994), "Quality practices of Indian organizations:

39. an empirical analysis”, International Journal of Quality \& Reliability Management, Vol. 11 No. 1, pp. 38-52.

40. Moon, P. (1993). Appraising Your Staff. Kogan Page, London.

41. Mital, A., Pennathur, A., Huston, R.L., Thompson, D., Pittman, M., Markle, G., Kaber, D.B.,Crumpton, L., Bishu, R.R., Rajurkar, K.P., Rajan, V., Fernandez, J.E., McMulkin, M., Deivanayagam, S., Ray, P.S. and Sule, D. (1999),The need for worker training in advanced manufacturing technology (AMT) environments: a white paper, International Journal of Industrial Ergonomics, Vol. 24, No. 2, pp.173-184. 
42. Nair, Anand. 2006. "Meta-analysis of the Relationship between Quality Management Practices and Firm Performance Implications for Quality Management Theory Development.” Journal of Operations Management 24 (6): 948-975.

43. Oakland, J. S. (1993). Implementation of TQM and Management of Change, Total Quality Management: The Route to Improving Performance Jordan Hill, Oxford: Butterworth Heinemann Ltd.

44. Odukoya, Jonathan Adedayo, et al. "Employers'perception of Covenant University Graduates." IASET: International Journal of Library and Educational Science 2.3 (2016).

45. Prajogo, D.I. \&Sohal, A.S. (2006) 'The relationship between organization strategy, total quality management (TQM), and organization performance-the mediating role of TQM', European Journal of Operational Research, vol. 168, no. 1,pp. 35-50.

46. Prajogo, D.I. and Sohal, A.S. (2004), "The multi dimensionality of TQM practices in determining quality and innovation performance - an empirical examination”, Technovation, Vol. 24 No. 6, pp. 443-53.

47. Pfeffer, J. \& Sutton, R.I. (2006) 'Evidence-based management', Harvard business review, vol. 84, no. 1,p. 62

48. Prajogo, D.I. \& Cooper, B.K. (2010) 'The effect of people-related TQM practices on job satisfaction: a hierarchical model', Production Planning and Control, vol. 21, no. 1,pp. 26-35

49. Rakesh Kumar, R.S.Mishra, "Total Quality Management: model and flexible framework for performance improvement", International Journal of Research and Analytical Reviews (IJRAR), E-ISSN 2348-1269, P- ISSN 2349-5138, Volume.6, Issue 2, Page No pp.867-874, June 2019, DOI: http://doi.one/10.1729/Journal.23462

50. Rao, S. Subba, Luis E. Solis, and T. S. Raghunathan. 1999. "A Framework for International Quality Management Research: Development and Validation of a Measurement Instrument.” Total Quality Management 10 (7): 1047-1075

51. Scannell, T.V., Vickery, S.K., and Droge, C.L., 2000. Upstream supply chain management and competitive performance in the automotive supply industry. Journal of Business Logistics, 21 (1), 23-48.

52. Solis, Luis E., T. S. Raghu-Nathan, and S. Subba Rao. 2000. “A Regional Study of Quality Management Infrastructure Practices in USA and Mexico.” International Journal of Quality \& Reliability Management 17 (6): 597-614

53. Slappendel, C. (1996), "Perspectives on innovation in organizations”, Organization Studies, Vol. 17 No. 1, pp. 107-29.

54. Soltani, E., van der Meer, R., \& Williams, T. M. (2005). A Contrast of HRM and TQM Approaches to Performance Management: Some Evidence*. British Journal of Management, 16(3), 211-230. doi:10.1111/j.1467-8551.2005.00452.x

55. Seetharaman, A., Sreenivasan, J., \& Boon, L. P. (2006). Critical Success Factors of Total Quality Management. Quality \& Quantity, 40(5), 675-695. doi:10.1007/s11135-005-1097-2

56. Sulphey, M. M. "The utility of Q-methodology in Human Resource Management research." International Journal of Human Resources Management 3.3 (2014): 15-26.

57. Saldana Delia (2001), “ cultural competency a practical guide for mental health service providers “, Hogg Foundation for Mental Health, The university of Texas at Austin, pp. 1-30.

58. Saaty,T.L.(1980), The Analytic Hierarchy Process, McGraw-Hill,NewYork,NY.

59. Saaty,T.L.(1994), “How to make a decision: The Analytic Hierarchy Process”, Interface, Vol.24 No.6,Pp. 19-43.

60. Singh, Komal, and AkshayDeokar. "Effects of 5 S Implementation on Performance of Organization." International Journal of Business and General Management (IJBGM) 7.2 (2018): 1-14.

61. Saaty, T. L., \& Peniwati, K., (2007).Group decision making. Pittsburgh: RWS. 
62. Tüysüz, F., \& Şimşek, B. (2017). A hesitant fuzzy linguistic term sets-based AHP approach for analyzing the performance evaluation factors: an application to cargo sector. Complex \& Intelligent Systems, 3(3), 167-175. doi:10.1007/s40747-017$0044-x$

63. Vanichchinchai, A., \& Igel, B. (2011). The impact of total quality management on supply chain management and firm's supply performance. International Journal of Production Research, 49(11), 3405-3424. doi:10.1080/00207543.2010.492805

64. Van Schalkwyk, J. (1998). Total quality management and the performance measurement barrier. The TQM Magazine, 10(2), 124-131.

65. Walsh, A., Hughes, H., \& Maddox, D. P. (2002). Total quality management continuous improvement: is the philosophy a reality? Journal of European Industrial Training, 26(6), 299-307.

66. White, M.A. and Nebeker, D.M. (1996), “Team-oriented performance management: an alternative to traditional performance appraisal”, in Knouse, S.B. (Ed.), Human Resources Management Perspectives on TQM, Concepts and Practices, ASQC Quality Press, Milwaukee, WI, pp. 193-215.

67. Yildirim, B. F., \& Adiguzel Mercangoz, B. (2019). Evaluating the logistics performance of OECD countries by using fuzzy AHP and ARAS-G. Eurasian Economic Review. doi:10.1007/s40822-019-00131-3

68. Zbaracki, M.J. (1998) 'The rhetoric and reality of total quality management', Administrative Science Quarterly, pp. 602-636.

69. Zadeh, L. (1965). Fuzzy sets. Information Control, 8, 338-353.

\section{AUTHOR BIOGRAPHIES}

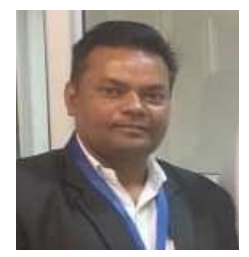

Mr. Rakesh Kumar Graduated in Industrial Engineering and Master's in Mechanical Engineering with specialization in Computer Integrated Manufacturing from India. He also obtained PGD in IPR. He is currently an Assistant Professor and research scholar at Delhi Technological University in Department of Mechanical. His research interest includes Total Quality Management, Reliability Engineering, Operations and Supply chain management, Fuzzy Logic, AI and Decision Science and Intellectual Property Rights.

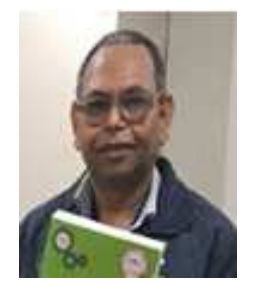

R.S. Mishra (Professor) received the Ph.D. degree in Mechanical engineering from IIT Delhi, India and currently at Delhi Technological University serving since 1997. He having 150 research papers in peer reviewed in International journals and 75 research papers in proceedings of International and National conferences. Prior to joining DTU, he served 09 years at different engineering colleges of India, viz, REC Hamirpur, PAU Ludhiana (Punjab) and HAU, Hisar (Haryana.) 